\title{
A co-evolutionary model of newcomers' psychological contract formation: the role of social networks
}

Article

Accepted Version

Erdem, C. and Bankins, S. (2018) A co-evolutionary model of newcomers' psychological contract formation: the role of social networks. Academy of Management Proceedings, 2018 (1). 16650. ISSN 2151-6561 doi:

https://doi.org/10.5465/ambpp.2018.16650abstract Available at https://centaur.reading.ac.uk/79017/

It is advisable to refer to the publisher's version if you intend to cite from the work. See Guidance on citing.

To link to this article DOI: http://dx.doi.org/10.5465/ambpp.2018.16650abstract

Publisher: Academy of Management

All outputs in CentAUR are protected by Intellectual Property Rights law, including copyright law. Copyright and IPR is retained by the creators or other copyright holders. Terms and conditions for use of this material are defined in the End User Agreement.

www.reading.ac.uk/centaur 
Central Archive at the University of Reading

Reading's research outputs online 


\section{A Co-Evolutionary Model of Newcomers' Psychological Contract Formation: The Role of Social Networks}

$\underline{\text { Authors }}$

Ceren Erdem, Henley Business School, U. of Reading, c.erdem@henley.ac.uk

Sarah Bankins, Macquarie U., sarah.bankins@mq.edu.au 
A Co-Evolutionary Model of Newcomers' Psychological Contract Formation: The Role of Social Networks 


\begin{abstract}
The psychological contract, the perceived mutual obligations between employer and employee, is a critical construct for understanding employment relationships and how their management informs employees' attitudes and behaviors. Extensive work has focused on the outcomes of the contract's operation, but there remains a paucity of research examining its formation and the role of 'others', within and outside the organization, in the development process. While important work has drawn on social network theorizing to explore how social interactions shape contract perceptions, the relationships posited remain largely uni-directional, highlighting another overarching limitation in the contract literature: a lack of dynamic theorizing. To address these gaps, our conceptual paper adopts a process-based lens to calibrate a co-evolutionary model of contract formation that explicates the reciprocal relationship between newcomers' social networks and their psychological contract development. Grounded in a structuration perspective (Giddens, 1976), we draw on a range of dynamic theories to move the contract literature beyond examining static relationships to comprehensively theorize contracting as a process co-evolving with social network development in early socialization stages. We conclude by highlighting the theoretical and practical implications of our model.
\end{abstract}

Keywords: Psychological contract formation; newcomers; retrospective and prospective sensemaking; social networks; co-evolutionary model 


\section{INTRODUCTION}

The psychological contract consists of perceived mutual obligations between the focal individual and the organization (Rousseau, 2001). The contract provides an explanatory framework for exploring the employment relationship and how changes and discrepancies in perceptions of these mutual obligations shape employees' attitudes and behaviors, such as turnover, job satisfaction (Rousseau, 1995), commitment and organizational citizenship behaviors (Conway \& Briner, 2005; Coyle-Shapiro \& Kessler, 2000) It is largely agreed in the literature that contracting embodies an unfolding, dynamic process in which its terms are formed, changed, met or unmet and revised over time (Conway \& Briner, 2005).

The plethora of contract research has, to date, predominantly focused on the processes of contract breach and violation, its relationship to other contextual variables and the attitudinal and behavioral aftermath of these events (Rousseau, 2001; Bankins, 2015). This rich theoretical and empirical work has contributed substantially to our understanding of the properties of the contract and its outcomes; however, understanding the contract as a dynamic and ongoing process, particularly during contract formation, requires much further work. An ongoing criticism in the contract literature is its predominant focus upon linear cause-and-effect relationships (Conway \& Briner, 2005); particularly as recent scholarship demonstrates that much more complex relationships underlie the functioning of the contract, challenging researchers to adopt more processual, cyclical and recursive theoretical lenses and methodologies to model this complexity (e.g. Griep \& Vantilborgh, 2018).

Further, gaps remain in our knowledge of a key component of the contracting process: its formation and the role of others within that process. Psychological contract formation focuses on identifying and refining the obligations exchanged by newcomers and organizational insiders 
during the 'phases of pre-employment, recruitment, early socialization and later experiences' (Rousseau, 2001: 512). At these times, newcomers engage in active information seeking and the significant role of organizational insiders here, and potentially 'outsiders', is acknowledged and demonstrated by many researchers studying contract formation (e.g. Tomprou \& Nikolaou, 2011). For example, De Vos, Buyens, and Schalk (2003) show contract formation involves individuals altering their contracts both in response to feedback from others and proactively on their own, while Thomas and Anderson (1998) demonstrate that changes in new recruits' expectations are towards the insider norms of experienced colleagues.

Drawing specifically on social network research Ho and Levesque (2005), Ho, Rousseau, and Levesque (2006) and Dabos and Rousseau (2013) show that individuals' social network positions, such as their friendship versus advice ties, influence the type of contract obligations they perceive and that individuals' social referents influence their perceptions of contract fulfillment. While this work importantly demonstrates that newcomers are indeed sensitive to interactions with, and information gleaned from, insiders (and potentially outsiders), there is much room remaining to explore how this process informs contract formation from a dynamic perspective.

For example, social network theory offers an important lens through which to explore how the type, number, structure and relational content of an individual's connections to others (organizational insiders and outsiders) influences contract development. But while social network theory has been fruitfully applied in contract research (as identified above), it usually investigates network effects once people are embedded in organizations, arguably well beyond the contract formation stage. This work also reflects a dominant, but often implicit, position in the contract literature: that individuals are generally passive contracting participants, with their agency neither explicitly accounted for nor conceptualized (Seeck \& Parzefall, 2008). It is only relatively recently 
that individuals have been centrally positioned as proactive agents in the construction of their contracts (Bankins, 2015; Tomprou, Rousseau, \& Hansen, 2015).

Overall, although other bodies of literature are increasingly exploring how one phenomena may reciprocally influence the development of another through co-evolutionary and agentic processes (e.g. Tasselli, Kilduff, \& Menges, 2015), the application of this dynamic perspective to psychological contracting remains missing. More specifically, at present, while important work has explored the role of social influences in shaping contract perceptions (e.g. Dabos \& Rousseau, 2013; Ho, 2005), our integration of network theorizing remains largely one-way, with a relative absence of dynamic theory to investigate the likely co-evolving nature of individuals' contract perceptions and their social network ties. This leaves the complexity of these relationships undertheorized and largely untested. It is at this juncture that we position our research.

To further develop our understanding of contract formation through a process-based and dynamic lens, we calibrate a co-evolutionary process model of contract formation that explicates the reciprocal relationship between newcomers' social networks and their psychological contract development. Grounded in a structuration perspective (Giddens, 1976), we draw on a range of dynamic theories to demonstrate how newcomers actively seek contract-related information through, and by forming and leveraging, social network connections with others within and outside their organizations. Given our co-evolutionary focus, we also theorize how newcomers' pre-entry expectations influence who they choose to form social network connections with, which in turn influences their developing contract perceptions. Put simply, this paper proposes that newcomers' psychological contracting and social network relationships initiate each other's formation and coevolve during the socialization stages of an employee's tenure. 
This work offers critical, process-oriented contributions to the psychological contract literature. In line with Rousseau's (2001: 512) assertions, this paper draws attention to the 'antecedents of the psychological contract...' by postulating a theoretical model capturing how and why the nature of social relationships are an important building block for psychological contract formation. Indeed, we draw on a bi-temporal understanding of sensemaking (Weick, 1995), that it is both retrospective and prospective in nature, to explain how newcomers make sense of the different information received from different social network connections. Further, by focusing on the unfolding, ongoing and continuous episodes of action and cognition in sensemaking (Weick, 1995), this paper moves the contract literature beyond examining uni-directional relationships between social networks and contracts to comprehensively theorize how they influence each other's evolution simultaneously in early socialization stages.

\section{THEORIZING PSYCHOLOGICAL CONTRACT AND SOCIAL NETWORK FORMATION AS A DYNAMIC, CO-EVOLUTIONARY PROCESS}

Studying co-evolutionary processes means exploring how variable $x$ influences variable $y$, while simultaneously exploring how $y$ reciprocally shapes $x$. These questions regarding how individuals influence, and are influenced by, their environment endure across many areas in the social sciences (Lazer, Rubineau, Chetkovich, Katz, \& Neblo, 2008), particularly in social network research. However, studying phenomena in this dynamic way requires researchers to set appropriate theoretical foundations and explicate mechanisms driving the posited change, by implementing flexible conceptual tools to account for growth and development in the focal areas. We first provide the theoretical underpinnings and mechanisms grounding and guiding our process model before specifying the model and positing the reciprocal relationships between our focal phenomena. 


\section{Theorizing Co-evolution: Structuration Theory}

Giddens' $(1976,1991)$ structuration theory is a conceptual driving force for addressing questions regarding the reciprocal individual-environment relationship, as it forms the basis for exploring 'bottom-up and top-down influence processes between individual agency and social structure' (Tasselli et al., 2015). Here, agency is situated at the micro-level and refers to individual actors and their choices and behaviors (Borgatti, Brass, \& Halgin, 2014). Structure, although construed broadly, relates to influences such as rules, regulations, social structures and other macro-level 'supra-structures' that individuals are unavoidably embedded within and that facilitate and constrain micro-level behavior (Borgatti et al., 2014).

A key tenet of structuration theory, highlighting its usefulness for theorizing coevolutionary processes, is that Giddens (1991) does not afford primacy to either agency or structure in generating outcomes. Instead, a 'dual feedback-feedforward' mechanism mutually generates each aspect, such that agents are both shaped by, and shape, structures and structures conversely shaping, and being shaped by, agents in a reciprocal and ongoing cycle (Jenkins, 2014). For us, this means social network characteristics form the focal 'structure' component within which individuals operate, that can both facilitate and constrain individuals' goal attainment through their psychological contract development. Conversely, individuals' contracts are not only shaped by the network structure in which they are embedded but, through exercising the 'agency' component, through creating the networks they operate within to best achieve their psychological contract goals. In grounding our co-evolutionary model in structuration theory, we now more deeply conceptualize the 'agency' (psychological contract) and 'structure' (social network) components of the model. 


\section{The Psychological Contract: 'Agency’ and the Micro Change Mechanism}

\section{(Contract $\rightarrow$ Network)}

We theorize psychological contracts to be goal-oriented schemas (Dabos \& Rousseau, 2013; Bankins, 2015), reflecting the perceived obligations forming the basis for exchanges between employer and employee. At the 'agency' level, we posit that a goal-directed, teleological mechanism drives the way in which psychological contracts influence social networks (contract>network). Van de Ven and Poole's (1995: 511) teleological 'motor' suggests change is driven by goal attainment, with individuals agentic, purposive and goal-directed drivers of change in a focal outcome. This contract conceptualization accords with Dabos and Rousseau's (2013) work identifying that contract terms can comprise resources that are finite and competitively sought by employees (such as promotions) and noncompetitive resources widely available across an organization (such as supportive work relationships). This further aligns with Rousseau's (2000) original relational-balanced-transactional contract term typology, whereby contracts premised upon the receipt of competitive resources align with balanced (flexible, development-focused) and transactional (limited scope, economic exchange) contract content and contract premised upon the receipt of non-competitive resources aligns with relational (long-term, support-focused) contract content. Further, according to Shea and Fitzsimons (2016: 45), 'goals are cognitive representations of desired end-states' and broadly encompass: individual advancement (individually-oriented towards achievement) and interpersonal affiliation (oriented towards forging connections with others).

Taken together, to connect contracting to a teleological change mechanism, we link contract terms to goal attainment by conceptualizing contracts as being based upon competitive resources (balanced and transactional contracts) relating to advancement goals and contracts based upon non- 
competitive resources (relational contracts) relating to interpersonal affiliation goals. Overall, we suggest that individuals' agency and behaviors are directed toward goal fulfillment, manifested in their psychological contracts, which influences how individuals then shape their social network configurations.

\section{Social Network Characteristics: 'Structure' and Macro Change Mechanisms (Network $\rightarrow$ Contract)}

Social tie connections significantly affect our access to a range of resources and information, as well as the attitudes and beliefs that we form (Morrison, 2002). While a range of generative mechanisms have been identified to explain these effects (Contractor \& Monge, 2002), social network effects broadly operate via two mechanisms - selection and influence. This reflects an enduring question in network research, do we create ties with others who are like us (selection), or do we become more like those we are connected to (influence)?

Overarching both selection and influence is the mechanism of social capital generation. Social capital refers to the value individuals generate and extract from their social networks, including relational (such as social support) and instrumental/material (such as informational, financial) resources (Burt, 2000). At early organizational socialization stages, research suggests newcomers will particularly seek to build and access social capital, as they likely begin with little (Fang, Duffy, \& Shaw, 2011). Indeed, Seibert, Kraimer, and Liden (2001: 219) identify that, in terms of career development and mobility, the effect of social capital manifests through access to information, resources and sponsorship, offering enhanced role and work performance and career satisfaction (Morrison, 1993). The generation and accumulation of social capital is also critical for goal attainment (Sandefur \& Laumann, 1998), aligning with our teleological (micro-level) change mechanism. 
Social capital involves bonding, bridging and linking types (Gittell \& Vidal, 1998). Network structures and ties that facilitate bonding social capital are 'relatively closed and inwardlooking' (Nahapiet, 2011: 242) and refer to 'resources that people can obtain from within-group ties' (Yuan \& Gay, 2006: 1067), generating Burt's (2000: 351) benefits of 'network closure'. This capital is created through reciprocal exchanges of resources such as trust, socio-emotional support, the direct and expedient flow of reliable information and the creation of strong shared norms through group cohesion (Nahapiet, 2011; Yuan \& Gay, 2006). However, a drawback is that information is likely not novel and potentially redundant (Burt, 2000).

Structures and ties that facilitate bridging social capital 'span diverse groups, connecting normally separate people' and refer to 'resources that people can gain from their ties with people from the outside' (Yuan \& Gay, 2006: 1067), linking to Burt's (2000: 353) benefits of 'network brokerage'. This type of capital provides access to greater non-redundant information volume, greater likelihood of access to new opportunities and resources and the ability to combine and broker knowledge across unconnected networks (Burt, 2000). Finally, linking social capital is a form of bridging capital and refers to network structures and ties connecting an individual to dissimilar others in positions of power and authority (Scott \& Hofmeyer, 2007) which, like bridging capital more broadly, offers access to critical resources, information and opportunities (Hawkins \& Maurer, 2009). This form of capital allows for an exploration of the ways in which newcomers utilize the 'sponsorship' or 'borrowed social capital' (Jokisaari \& Nurmi, 2009: 90) of more powerful others in the socialization process.

The way in which selection and influence, and more broadly social capital, operate can be delineated across structural and relational network components. Structural characteristics focus on 'impersonal characteristics of the networks', whereas relational characteristics 'concern the quality 
of a relationship between people' (Jokisaari \& Nurmi, 2012: 81). For our model, we draw on two structural network characteristics (influence mechanism) and two relational network characteristics (selection mechanism), as each generates social capital to facilitate goal attainment, but may also shape the types of goals sought.

Structural network characteristics. Network centrality is a core concept in social network theory and refers to the number of connections that one individual has to other individuals, as a measure of how 'central' an individual is in a network (Ibarra, 1993; Ibarra \& Andrews, 1993). Indegree centrality refers to the number of others that approach the focal individual for advice or support and out-degree centrality refers to the number of others that a focal individual is linked to (Tsai, 2001). High in-degree centrality generally means an individual is quite significant in a network (many others come to them) and high out-degree centrality means that an individual is likely to wield relatively more influence than non-central individuals (they can go to many others) (Sparrowe, Liden, Wayne, \& Kraimer, 2001). As a network location, centrality has been shown to provide a range of benefits and access to a broad range of social capital (Kovanovic, Joksimovic, Gasevic, \& Hatala, 2014).

Network density identifies which actors in a network are connected (or not) to other actors in that network. Dense networks are characterized by short paths between actors, support, trust and efficient communication (Rowley, 1997), are likely to form cliques or sub-groups and facilitate a higher number of connections between actors (Brass, Butterfield, \& Skaggs, 1998). Conversely, sparse network groups are characterized by fewer links between a wider range of actors, inviting a wider flow of information, resources and access to opportunities (Podolny \& Baron, 1997). Dense and sparse networks, respectively, generate bonding and bridging/linking forms of social capital (Nahapiet, 2011). 
Relational network characteristics. Granovetter's (1973) seminal work on the 'strength of weak ties' highlights how tie strength significantly and differentially generates different resources and individual outcomes. The degree of tie strength (strong or weak) between actors is an amalgam of the time, emotional intensity, intimacy, reciprocity and mutuality characterizing a relationship (Granovetter, 1973). Strong ties often connect dense networks and while offering socio-emotional resources, 'primarily convey redundant, within-group information'. Weak ties often connect sparse networks and, although easily broken, 'are sources of new information' (Podolny \& Baron, 1997: 674 ) and resources. Strong ties generally build bonding social capital, whereas weak ties generate bridging social capital.

Finally, homophily is a highly influential, relational-level social network concept premised on the notion that 'like attracts like', whereby individuals who are similar in traits (such as gender, race) are more likely to interact with and develop stronger ties with each other (Jokisaari \& Nurmi, 2009). Other attributes, such as values, goal preferences, academic achievement and a range of other attitudes (Smirnov \& Thurner, 2016) can also form the basis for homophilous ties. Structural homophily exists when individuals change their attitudes and beliefs in line with the social network in which they are embedded and choice homophily exists when individuals adapt their social networks to form connections with others who share similar traits and attributes. Homophily particularly underpins the development of bonding social capital (Yuan \& Gay, 2006).

\section{Sensemaking: The Basis for Contract $\leftarrow \rightarrow$ Network Co-Evolution}

With 'agency' and 'structure' components in place, we now draw on a temporally expanded conceptualization of sensemaking, and incorporate cybernetic principles, to explain the interactive (feedback-feedforward) nature of agency and structure in shaping the co-evolution of newcomers' psychological contracts and social networks. Based on Weick's (1995) seminal work, individuals 
engage in sensemaking to construct plausible meanings from uncertain situations, making it a dynamic conceptual tool to explore unfolding processes (Conway \& Briner, 2005). Sensemaking is utilized in contract research to understand how employees interpret, respond and give meaning to information gathered (De Vos \& Freese, 2011). The enactment (individuals combine action (through agency) and cognition) and social (interactions with others shape interpretation) properties of sensemaking reinforce the role it likely plays in co-evolutionary processes.

Given structuration theory is premised on feedback and feedforward mechanisms (Giddens, 1991; Stones, 2005), we ‘temporally stretch’ Weick’s (1995) sensemaking beyond its retrospective focus (sense is made based on interpreting 'what has passed') to also incorporate a prospective component. Prospective sensemaking involves considering 'the probable future impact of certain actions and especially non-actions, on the meaning construction process' (Gioia, Thomas, Clark, \& Chittipeddi, 1994: 378), generating interpretations that project images of future states (Gephart, Topal, \& Zhang, 2010). Given sensemaking involves action and agency, the literature increasingly recognizes that individuals can take a variety of temporal orientations (Maitlis \& Christianson, 2014), in retrospect and prospect, as 'anticipating what may come next is a distinguishing aspect of the temporality of human existence' (Sandberg (Sandberg \& Tsoukas, 2015: 24). Hence, because we position contracts as goal-directed incorporating a prospectively-oriented sensemaking stance is necessary and timely.

Finally, to explain how retrospective and prospective sensemaking interact to inform coevolution we draw on cybernetic principles. Cybernetic theories suggest that through selfregulating processes individuals seek feedback from their environment and compare this to a 'reference standard or goal' (Direnzo \& Greenhaus, 2011: 571), generating a negative or positive feedback loop (discrepancy). Any discrepancy identified results in action taken to address it 
(Direnzo \& Greenahus, 2011). While feedback is a retrospective process, focused on evaluating past performance (Tadepalli, 1992) cybernetic theory also recognizes adaptive cognitions and behaviors through a prospective, feedforward process (Tadepalli, 1992). Feedforward control focuses on the 'continuous evaluation of plans', identifies how current behavior enables goal achievement and detects and corrects disturbances prior to discrepancies occurring (Tadepalli, 1992).

Therefore, within our model we suggest individuals' psychological contracts form the goaldirected 'standard' against which environmental information is compared. At the micro-, or agency, level it is the contract that identifies the plans and goals forming the basis for prospective sensemaking through a feedforward process. In this process individuals exert their agency, taking their goals as a basis for social network development. At the macro-, or structure, level we suggest that information gained through social network interactions, and the position of individuals in those networks, then provides critical feedback forming the basis for retrospective sensemaking. Here, individuals gain an understanding of how and whether their network characteristics, and the social capital generated, are facilitating the fulfillment of their goal-based contracts. Overall, it is at the intersection of these feedback-feedforward loops, underpinning the retrospective and prospective sensemaking process, that will inform the way individuals evaluate information received, the outcome of their behaviors (Fang, Evans, \& Landry, 2005) and ultimately guide the co-evolution of their psychological contracts and social networks. 


\section{CONCEPTUAL MODEL: CO-EVOLUTION OF NEWCOMERS' PSYCHOLOGICAL CONTRACTS AND SOCIAL NETWORKS}

As depicted in Figure 1, this section introduces our co-evolutionary process model of newcomer's psychological contract and social network development through the lens of sensemaking. We focus our theorizing on organizational newcomers who are new to the organization, new to employment relationships generally and are predominantly entering relatively junior roles, as the dynamic aspects of psychological contracting are most apparent in this cohort (Rousseau, 1995, 2001). Further, although not without criticism, much of the contract literature has studied this cohort, allowing us to draw on established research to ground our hypotheses.

Insert Figure 1 about here

We now develop our hypotheses through two critical stages of newcomer socialization: the anticipatory stage (also termed 'pre-entry') and the encounter stage (also termed 'post-entry). The anticipatory stage occurs in the weeks (and possibly months) before joining an organization, when an individual has accepted a position but can only anticipate their experiences (Louis, 1980). The encounter stage occurs over the first 6-10 months following organizational entry and is 'critical in shaping the individual's long-term orientation to the organization' (Louis, 1980: 231). While a third socialization stage, acquisition, exists towards the end of the first year of employment, this is generally characterized by greater stability and reduced sensemaking (De Vos et al., 2003) and individuals have largely moved from 'newcomer' to 'insider' (Louis, 1980: 231). Therefore, we focus on the anticipatory and encounter (pre- and post-entry) stages as they involve the use of extensive sensemaking and intense information-seeking (Thomas \& Anderson, 1998). For each 
socialization stage, we develop hypotheses focused on how psychological contract perceptions shape individuals' social network development (contract->network) and then, reciprocally, how individuals' social networks shape psychological contract perceptions (network->contract).

\section{Anticipatory Stage: Psychological Contract->Social Network}

At organizational pre-entry newcomers face high levels of uncertainty in their employment relationships. They have not yet entered the organization, commenced their role, met any (or very few) colleagues and they may or may not have met their supervisor. Also, the main goal-related needs of individuals will be sourcing reliable and credible information to confirm their choice of employer will assist them to meet their desired goals and contract terms. Combined, this creates much room for uncertainty and for individuals' social networks to 'fill the void'.

At this socialization stage, individuals will hold what is termed an anticipatory psychological contract (APC). The APC develops 'independently from the specific context of an employment relationship' (De Vos, De Stobbeleir, \& Meganck, 2009: 290); that is, individuals are not yet situated in an employment relationship and so form their APC by drawing inferences, via prospective sensemaking particularly, about what may occur within it. Prior to entering an organization, individuals are unlikely to have extensive (or indeed any) intra-organizational networks, meaning they are likely to rely on extra-organizational networks as sources of information.

Throughout our framework we develop and draw on the notion of 'APC specificity'. Individuals differ in the specificity of the terms (content) of their psychological contracts, including their APCs. We draw on Rousseau's (2001: 511) seminal work on the 'building blocks' of psychological contracts and use her notion of schemas. Schemas refer to the "cognitive organization 
or mental model of conceptually related elements' and at this stage of socialization would be termed 'pre-employment schemas' (Rousseau, 2001: 513-516). The contract itself is often referred to as an employment-related schema (Shore \& Tetrick, 1994) and may be constituted by relatively few and simple components with limited linkages ('novice' schemas) or a greater quantity and complexity of components and linkages ('expert' schemas) (Rousseau, 2001). We suggest that these pre-employment schemas will inform individuals' degree of APC specificity. That is, individuals with 'simpler' pre-employment schemas ('novices') will experience less APC specificity, compared to 'experts' who hold more complex pre-employment schemas and thus experience higher levels of APC specificity.

In line with our micro-level teleological change motor, we suggest that some individuals will have higher APC specificity, and hence lower certainty regarding future employment relationships, because they have more fully formed employment-related goals to guide perceptions of reciprocal obligations with the employer (the psychological contract). For example, individuals possessing individual advancement goals related to promotion and financial rewards will, in line with (De Vos, Buyens, \& Schalk, 2005) findings that people search for information related to their goals, actively seek information regarding their employers' obligations in this area (balanced and transactional contract content). Conversely, other individuals may have less specific APCs potentially driven by minimal (or no) work experience at this career stage and/or not have particularly well-formed career goals, and hence lower certainty regarding future employment relationships. Indeed, Rousseau (2001) suggests that individuals with more or less prior work experience will hold different employment schemas.

APC specificity and the utilization of strong/weak ties. We first suggest that the degree of APC specificity will drive the social networks individuals utilize at this pre-employment stage. In 
particular, the level of uncertainty generated through more or less specific APCs, and more or less specific career goals, will likely impact the prospective sensemaking process particularly. If individuals are very clear about their career goals, which will inform their APCs, then they will have specific information to seek regarding what their future employer will offer them. We term this a 'single strand' of uncertainty. That is, individuals with more specific APCs will exhibit higher certainty about their APC content, but still have some degree of uncertainty about whether their future employer will fulfill their anticipations. Therefore, individuals with higher APC specificity will likely seek more specific information and so be more likely to target their weak tie network connections to access the bridging social capital and fuller, more diverse, more accurate and nonredundant information these ties provide.

Conversely, lower APC specificity means individuals will have higher levels of uncertainty influencing their prospective sensemaking toward future employment relationships. We term this 'double strand' uncertainty, with individuals exhibiting uncertainty regarding both their APC content and whether the future employer can fulfill their anticipations. This higher level of uncertainty, compared to those with higher APC specificity, means for these individuals to gain information from others they must divulge higher levels of vulnerability, insecurity and a lack of knowledge and will also be searching for more general, rather than necessarily specific, information. Research shows when individuals face high uncertainty and need to disclose a lack of knowledge, they are more likely to rely on trusted others through leveraging bonding social capital (Mizruchi \& Stearns, 2001). Hence, they will be more likely to utilize strong tie connections, characterized by higher levels of trust, comfort, support, reciprocity and norms of self-disclosure (Shah, 1998), to facilitate information-seeking regarding employment relationships and the future employer. 
Proposition 1: Individuals with higher (lower) APC specificity will have more specific (general) pre-entry employment-related information they are seeking and so will utilize weaker (stronger) network ties.

\section{Anticipatory Stage: Social Network ->Psychological Contract}

Network centrality (and strong/weak ties) and APCs. At the pre-entry stage, we focus on out-degree centrality and link this to the relational network characteristic of weak ties. Research suggests individuals with high out-degree centrality are more likely to hold a higher number of weak tie connections in their network (e.g. Hansen, 1999; Levin \& Cross, 2004). This is because the higher the number of connections an individual has (higher centrality), the more difficult it is to sustain strong tie connections given the resources, time and energy required to maintain them (Granovetter, 1979). Therefore, when compared to individuals with low out-degree centrality, individuals with high out-degree centrality will likely have more weak tie connections within their networks and so higher access to bridging social capital and its benefits.

Thus, those with higher out-degree centrality (and thus more weak ties) will have access to the attendant advantages of a greater volume, diversity and accuracy of information (Granovetter, 1979) regarding employment generally and certain types of jobs, more specifically, to inform their career goals and subsequent APCs. Higher out-degree centrality means individuals will have the ability to 'reach out' to a wider range of network contacts in the pre-entry stage and likely facilitate higher APC specificity, when compared to individuals with low out-degree centrality (fewer weak ties).

Proposition 2: Individuals with high (low) out-degree centrality will have higher (lower) APC specificity compared to individuals with low (high) out-degree centrality. 


\section{Encounter Stage: Psychological Contract->Social Network}

Pre-entry APC specificity and (choice) homophily. Homophily occurs when individuals change their attitudes and beliefs in line with the social network in which they are embedded (structural homophily) or via 'social selection' (Smirnov \& Turner, 2016: 2) whereby individuals adapt their social networks to link with others who share similar traits and attributes (choice homophily). We suggest that for those individuals with higher APC specificity at the pre-entry stage, this will drive them to develop networks with others who share similar goals and psychological contract content via choice homophily. We further propose that individuals who lower APC specificity at the pre-entry stage will still be influenced by choice homophily, but that the attribute similarity driving this will be less focused on career goals and psychological contract content (as these are less well formed) and instead be more focused on general demographic characteristics and belief structures, for example characteristics such as age, educational background, etc.

Proposition 3: Individuals with higher (lower) APC specificity at the pre-entry stage are more likely to create connections with individuals with similar traits and attributes relating to career goals and psychological contract content (general demographic characteristics) post-entry.

Psychological contract terms and network development. The types of goals individuals hold will influence the psychological contract with their employer and will attune them to organizational information that is most relevant for goal achievement (De Vos et al., 2005). Therefore, the types of goals individuals hold when entering an organization will inform their psychological contracts and, we argue, the type of networks they develop. Given our theorizing focuses on individuals who are new to employment relationships generally, we suggest they will 
often be developing their intra-organizational networks 'from scratch'. We suggest that both individuals with more or less specific APCs will hold some type of goals (broadly and weakly held or more specifically and strongly held, respectively) and so our theorizing here relates to both types of individuals.

We suggest that goals focused on achieving interpersonal affiliation such as, from a PC perspective, generating mutual support, care, consideration and loyalty through the development of relational contract content will look to develop strong ties. These ties generate the bonding social capital required to achieve these types of outcomes and 'deliver' these types of resources across an individual's network. For example, given that strong, friendship ties center on mutual trust, affect and frequency of interaction, this type of network structure will facilitate the achievement of psychological contract terms that are focused on interpersonal affiliation goals.

Proposition 4: Individuals holding interpersonal affiliation goals, and hence more relational psychological contracts, will seek to develop strong ties in their workplace social networks.

Conversely, if a newcomer's goals focus on individual advancement, and more balanced and possibly transactional contract content, we suggest they will likely seek to identify and cultivate weak tie relationships. These ties generate the bridging social capital that generates the resources needed to achieve these types of job-related goals. For example, in a similar vein, Ho and Levesque (2005) found that employees look to structurally equivalent others when assessing job-related psychological contract obligations, as these individuals are located in comparable positions in the organizational hierarchy. Because developing weaker ties also facilitates access to a greater diversity of information, more accurate and timely information and a wider range of people, this 
will provide individuals with access to knowledge that can facilitate the identification of career progression and development opportunities.

Proposition 5: Individuals holding individual advancement goals, and hence more balanced and/or transactional psychological contracts, will seek to develop weak ties in their workplace social networks.

Perceptions of psychological contract breach and network development. Employee perceptions of contract breach, or the lack of fulfilment of perceived employer obligations, are pervasive, regular and often prevalent following critical stages in the employment relationship, such as organizational entry, when uncertainty and ambiguity is high (Conway \& Briner, 2005). As a corollary to Proposition 1, and as reciprocally related to Proposition 7 , we suggest that individuals with lower APC specificity, and contracts formed based upon strong tie information, are more likely to experience feelings of ambiguity and uncertainty compared to counterparts with more specific APCs developed through weak tie information. This again relates to the generally more diverse, non-redundant and accurate information generated through weak ties, as opposed to strong ties. Given this, we suggest that those individuals with lower APC specificity, who activated strong tie networks at the pre-entry stage, will be more likely to experience feelings of breach postentry.

Proposition 6a: Individuals with lower (higher) pre-entry APC specificity will be more (less) likely to experience contract breach perceptions post-entry.

Further, given recent contract research shows one way individuals often cope with feelings of contract breach and violation is through accessing social support (e.g. Bankins, 2015), we also suggest that when individuals perceive contract breach at this employment stage that it will 
influence them to develop strong network ties post-entry. While the informational advantages of weak ties have been discussed, the supportive and trusting benefits of the bonding social capital realized through strong ties is also beneficial, particularly during periods of uncertainty and ambiguity (Jokisaari \& Nurmi, 2012; Kammeyer-Mueller, Wanberg, Rubenstein, \& Song, 2013; Louis, 1980; Nelson \& Quick, 1991) such as when contract breaches are perceived.

Proposition 6b: Individuals who experience contract breach post-entry will seek to develop strong network ties.

However, given the early stage of employment, we further suggest that because strong ties generally develop over an extended period of time, and following ongoing interactions, creating these types of ties at such an early stage of employment will likely be difficult. We suggest that to do this, individuals will rely on the generation of 'swift trust' to expedite the development of their strong ties (Meyerson, Weick \& Kramer, 1996). Swift trust involves 'a presumptive form of trust, whereby team members ... are required to suspend uncertainty in order to achieve the established goals' (Germain \& McGuire, 2014). Meyerson, Weick, and Kramer (1996) initially investigated the concept of swift trust in temporary organizational structures and conceptualized it as the quick formation of initial trust that provides immediate confidence, and these beliefs are then later verified or changed.

Proposition 6c: Newcomers' development of strong ties at this employment stage will depend upon the development of swift trust between the focal individuals. 


\section{Encounter Stage: Social Network->Psychological Contract}

Pre-entry use of strong/weak ties and psychological contract breach perceptions. Granovetter (1979) found that people who utilized weak ties in the job search process had higher levels of satisfaction in their new roles than individuals who had utilized strong ties (Lin, Ensel, \& Vaughn, 1981). Building on this, we suggest individuals who activate weak ties will have more accurate post-entry psychological contracts because of their access to fuller, more diverse and overall more accurate and less redundant information through their weak ties, and so be less likely to experience perceptions of contract breach.

For individual who utilized strong ties, the content of the information (accuracy and redundancy) is likely to be poorer compared to information sourced through weak ties. Therefore, we suggest that individuals who activate strong ties will have less accurate post-entry psychological contracts and so will be more likely to experience perceptions of contract breach. This theorizing complements Proposition $6 \mathrm{a}$ and the theorized co-evolving nature of contract content and organizational social networks. That is, the type of contract content will influence the type of network connections formed and, conversely, the type of networks formed and activated will influence the type of contract content.

Proposition 7: Individuals who activated more weak (strong) ties at the pre-entry stage will have lower (higher) perceptions of psychological contract breach during the post-entry socialization period.

The 'interactional zone': Where newcomers 'land' in the network landscape. When newcomers enter an organization, they enter into an already established 'network landscape'. As Jokisaari and Nurmi (2012: 87) state, 'people's social networks in the workplace are formed to a 
very large extent according to their formal position and location in the organization', or what Van Maanen and Schein (1979: 215) term the 'interactional zone'. This zone is particularly important to understand in relation to the co-evolving nature of psychological contracts and networks. That is, newcomers are likely to have very few (if any) intra-organizational networks, those they do have will be highly dependent upon the 'network landscape' in which they are initially situated and they will, at least to some degree, be dependent on this initial network structure for information and resources generated through the social capital provided. We focus here on two aspects of this 'network landscape': network centrality (through network 'sponsorship'); and (workgroup) network density.

Network centrality links to Schilling and Fang's (2013: 974) 'hubby' networks, with individuals deemed to be 'hubs' when they 'have significantly more connections than does the average (network) member. For newcomers, connections to these 'hubs' can provide access to linking social capital whereby one (usually more senior) individual assists another to develop network ties through accessing their own (Jokisaari \& Nurmi, 2012). While little empirical work explores the influence of 'sponsorship', it is recognized that assistance provided by others will be important for newcomers' network development (Jokisaari \& Nurmi, 2012).

Given this, we suggest that newcomers who have connections to 'hubby' individuals through their workgroup (or supervisor), will be more likely to develop, or further strengthen, goals related to individual advancement and development. This is because these newcomers will have a better 'view' of the opportunities available within their organization. This is supported by other research showing that individuals connected to highly central managers are more likely to be promoted, have higher pay and have better access to more prestigious and higher profile work (Katz, Tushman, \& Allen, 1995; Sparrowe \& Liden, 1997). 
Proposition 8a: Newcomers with access to 'hubby' people (in-degree or out-degree centrality) in their workgroup are more likely to develop higher individual advancement and development goals, compared to individuals without this access.

This relationship will, however, be moderated by the development of swift trust between the individual and focal network contact (highly central individual). That is, a degree of trust and perception of credibility is likely needed before others will leverage their networks for the advantage of another. This means the two individuals will need to begin developing a strong tie, as this results from trust and ongoing interactions and the freer sharing of information, support and resources.

Proposition 8b: The relationship at Proposition 8 will be stronger when swift trust is developed between the newcomer and the 'hubby' individual.

Finally, we focus on network density or sparseness. As identified earlier, dense networks can also be characterized as 'closed', in recognition of the process of transitivity (where friends of friends become friends) and often form cliques, particularly generating bonding social capital (Brass et al., 1998; Nahapiet, 2011; Rowley, 1997). However, key drawbacks of this type of network is the restricted flow of information they provide and the peer-related pressure to adopt the norms and shared identities of the group (Soda \& Usai, 1999). Conversely, sparse network groups, particularly those that include individuals that broker structural holes, invite a wider flow of information and access to opportunities, but generally have a less cohesive group structure (Podolny \& Baron, 1997). Linked to the notion of propinquity, we suggest that 'landing' in either of these network structures will affect newcomers' psychological contracting. Propinquity refers to the physical or psychological proximity (distance) between individuals (Byrne, 1961; Festinger, 1950). Related to homophily, individuals with higher levels of propinquity are more likely to adopt the beliefs and 
attitudes of those around them. We suggest the psychological proximity inherent in dense networks, versus sparse networks, will influence newcomer contracting through the likelihood of adopting the goals and psychological contract beliefs of others within their workgroups.

Proposition 9: Individuals located in workgroups with a sparse (dense) network structure are more (less) likely to adapt their psychological contracts to those of their workgroup colleagues.

\section{Sensemaking: Feedback and Feedforward}

Weick (1995: 55) explains sensemaking as: 'once people begin to act (enactment), they generate tangible outcomes (cues) in some context (social) and this helps them discover (retrospect) what is occurring (ongoing), what needs to be explained (plausibility), and what should be done next'. We now explicate the role of sensemaking within our propositions above through constructing a narrative, based on a newcomer (Sophie), to interrogate further our conceptual model and particularly surface the role of sensemaking within it.

Sophie has no previous work experience and is joining her first white-collar, professional organization in one month. It's a time of high uncertainty for her and with no previous work experience to reflect upon (retrospective sensemaking) and few contacts to draw upon (low network centrality), she relies on her family and close friends for guidance. Along with her own broad goal of 'working somewhere with friendly people', her family and friends tell her that her company is growing quickly and most people who work there get 'good training'. This information helps Sophie form some career-related goals and her (still general) APC, as she is already extracting cues from the environment (via her social networks) to form 'frames of reference' (Conway \& Briner, 2005: 150) to guide ongoing sensemaking. Taken together, this is shaping her prospective 
sensemaking because as her goals are forming she can 'project forward' in time and anticipate what her employment will be like.

Post-entry, Sophie begins making connections with others who are similar in age and work experience (homophily) and who are also newcomers to the organization. Given her broad preentry goal of 'wanting to work with friendly people' (affiliation goals), she starts spending significant time with these individuals (forming strong ties). However, she notices that managers don't seem friendly and are quite 'distant' (retrospective sensemaking cue, determining a breach). This feedback from her environment reinforces her focus on further developing connections with those around her where she has already started creating strong ties, as she anticipates they will help her realize her goal of working with friendly people (prospective sensemaking - feedforward process).

Further, Sophie's workgroup is very closely connected where 'everyone knows everyone' (dense network). Her colleagues all seem quite focused on gaining access to high-profile projects and career advancement and discuss this often within the team informally and at team meetings. This cue prompts Sophie to re-evaluate the focus of her career goals (retrospective sensemaking), as she has seen how satisfied her colleagues are with the workplace and the work they do and she, similarly, wants that experience herself (prospective sensemaking). All team members seem to rely on one senior colleague, Peter, who 'knows everyone and everyone knows him' ('hubby' individual) to access information and resources across the organization. Sophie begins developing a strong tie with Peter, as others in her team have begun 'vouching' for her, and so she begins imagining the new and exciting types of work she can do and the higher-level roles this will make her competitive for (contract adaptation through propinquity, prospective sensemaking). 
Taken together, this narrative begins demonstrating the co-evolutionary nature of psychological contract and social network development, driven by bi-temporal sensemaking incorporating feedback and feedforward loops in a cybernetic process. This suggests individuals form their psychological contracts during key socialization stages according to feedback from their social environment, which is compared against what they currently understand their contract terms to be. Reciprocally, and in a co-evolutionary sense, individuals also engage in a cybernetic comparison process through developing and revising their social network relationships according to feedback from the environment comparing how the information generated through these network connections informs and supports the formation and enactment of their contracts. Here, individuals' goal-focused contracts offer a feedforward device, allowing for assessments of discrepancies which can then result in actions such as adapting contract content (as Sophie began to do) or adapting social networks to provide what current ties do not.

\section{DISCUSSION}

This paper provides an important and timely contribution to the contract literature by adopting a dynamic and process-based perspective to explore a hitherto neglected aspect of contracting: that it is likely a co-evolving process in an organizational setting. Theoretically, our model offers a number of contributions. First, we adopt multiple and dynamic conceptual tools to help move the contract literature beyond predominantly static models to explore contracting as a temporal and fluid process. This area of contract literature is growing, and we believe that applying a coevolutionary lens will further prompt the field to adopt more process-based theoretical devices and develop more temporally-sensitive conceptualizations of psychological contracting as a process. Further, in grounding our model in structuration theory we do not place primacy on agency or structure in the co-evolutionary process, allowing for individuals to be positioned as active 
contributors, rather than passive reciprocators (Bankins, 2015), to their contracting process (Seeck \& Parzefall, 2008).

Further, we contribute to the comparative paucity of research deeply exploring the contract formation process and, particularly, the influence of insiders on this development. This is critically important for providing a more complete and precise picture of how psychological contracts operate within employment relationships (Rousseau, 2001). Also, in line with recent critiques of the application of sensemaking (e.g. Maitlis \& Christianson, 2014; Sandberg \& Tsoukas, 2015) we adopt and explore a temporally-extended notion of sensemaking by incorporating its prospective element. In contrast to much research focusing on sensemaking only after disruptive events, we also position sensemaking as an ongoing process occurring continuously during psychological contract formation, which itself is ongoing and unfolding (Conway \& Briner, 2005).

An intuitive path for future research is testing our proposed relationships and taking advantage of the sophisticated data analysis techniques now available to model co-evolutionary relationships. As is occurring in other contract research, more explicitly incorporating temporallysensitive concepts and methods to capture both past- and future-oriented cognitive mechanisms (such as retrospective and prospective sensemaking) would be beneficial. Adopting the coevolutionary lens more broadly, it would also be instructive to explore how other phenomena, beyond social network configurations, reciprocally develop alongside psychological contracts. Expanding the theorizing and investigation of these processes beyond newcomers would also glean more expansive insights into how the co-evolutionary process unfolds for other employee cohorts with likely demonstrably different social network configurations, such as more experienced workers. 
Practically, our model offers critical insights for organisations regarding, particularly, the influence of social network configurations within which newcomers 'land' and the influence these will likely have on a range of wider outcomes. For example, it is instructive for organisations to consider the effects of dense versus sparse networks in shaping the types of goals and contract content newcomers develop as a result of the types of connections these network structures generally form. Further, managers could consider the types of social capital that flow through different network structures and, if career advancement and development are viewed as critical for newcomers to develop expectations of, then configuring the social networks around those newcomers to guide them toward this type of contract content may be beneficial. Put another way, the management of social relationships within organisations is likely to be an efficient way of managing employees' psychological contracts.

Overall, we have sought to re-focus the contract literature on the contract formation process and explore this from a dynamic co-evolutionary perspective. We believe our process model provides a significant and timely contribution to the contract literature through a more comprehensive analysis of how social networks and psychological contracts reciprocally influence the development of each other. 


\section{REFERENCES}

Bankins, S. 2015. A process perspective on psychological contract change: Making sense of, and repairing, psychological contract breach and violation through employee coping actions. Journal of Organizational Behavior, 36(8): 1071-1095.

Borgatti, S. P., Brass, D. J., \& Halgin, D. S. 2014. Social network research: Confusions, criticisms, and controversies, Contemporary perspectives on organizational social networks: 1-29: Emerald Group Publishing Limited.

Brass, D. J., Butterfield, K. D., \& Skaggs, B. C. 1998. Relationships and unethical behavior: A social network perspective. Academy of Management Review, 23(1): 14-31.

Burt, R. S. 2000. The network structure of social capital. Research in organizational behavior, 22: 345-423.

Byrne, D. 1961. The influence of propinquity and opportunities for interaction on classroom relationships. Human Relations, 14(1): 63-69.

Contractor, N. S., \& Monge, P. R. 2002. Managing knowledge networks. Management Communication Quarterly, 16(2): 249-258.

Conway, N., \& Briner, R. B. 2005. Understanding psychological contracts at work: A critical evaluation of theory and research: Oxford University Press.

Coyle-Shapiro, J., \& Kessler, I. 2000. Consequences Of The Psychological Contract For The Employment Relationship: A Large Scale Survey*. Journal of Management Studies, 37(7): 903-930.

Dabos, G. E., \& Rousseau, D. M. 2013. Psychological Contracts and Informal Networks in Organizations: The Effects of Social Status and Local Ties. Human Resource Management, 52(4): 485-510.

De Vos, A., Buyens, D., \& Schalk, R. 2003. Psychological contract development during organizational socialization: adaptation to reality and the role of reciprocity. Journal of Organizational Behavior, 24(5): 537-559.

De Vos, A., Buyens, D., \& Schalk, R. 2005. Making Sense of a New Employment Relationship: Psychological Contract-Related Information Seeking and the Role of Work Values and Locus of Control. International Journal of Selection and Assessment, 13(1): 41-52.

De Vos, A., De Stobbeleir, K., \& Meganck, A. 2009. The Relationship Between Career-Related Antecedents and Graduates' Anticipatory Psychological Contracts. Journal of Business and Psychology, 24(3): 289-298.

De Vos, A., \& Freese, C. 2011. Sensemaking during organizational entry: Changes in newcomer information seeking and the relationship with psychological contract fulfilment. Journal of Occupational and Organizational Psychology, 84(2): 288-314.

Direnzo, M. S., \& Greenhaus, J. H. 2011. Job search and voluntary turnover in a boundaryless world: A control theory perspective. Academy of Management Review, 36(3): 567-589.

Fang, E., Evans, K. R., \& Landry, T. D. 2005. Control systems' effect on attributional processes and sales outcomes: a cybernetic information-processing perspective. Journal of the Academy of Marketing Science, 33(4): 553-574.

Fang, R., Duffy, M. K., \& Shaw, J. D. 2011. The organizational socialization process: Review and development of a social capital model. Journal of Management, 37(1): 127-152.

Festinger, L. 1950. The spatial ecology of group formation.(L. Festinger, S. Schachter, \& KW Back, Eds.) Social Pressure in Informal Groups, 141-161: Stanford University Press.

Gephart, R. P., Topal, C., \& Zhang, Z. 2010. Future-oriented sensemaking: Temporalities and institutional legitimation. Process, sensemaking, and organizing: 275-312.

Germain, M.-L., \& McGuire, D. 2014. The role of swift trust in virtual teams and implications for human resource development. Advances in Developing Human Resources, 16(3): 356-370. 
Giddens, A. 1976. Functionalism: Apr\&\#xe8;s la lutte. Social Research, 43(2): 325-366.

Giddens, A. 1991. Modernity and self-identity: Self and society in the late modern age: Stanford university press.

Gioia, D. A., Thomas, J. B., Clark, S. M., \& Chittipeddi, K. 1994. Symbolism and strategic change in academia: The dynamics of sensemaking and influence. Organization science, 5(3): 363383.

Gittell, R., \& Vidal, A. 1998. Community organizing: Building social capital as a development strategy: Sage publications.

Granovetter, M. 1979. The idea of" advancement" in theories of social evolution and development. American Journal of Sociology, 85(3): 489-515.

Granovetter, M. S. 1973. The strength of weak ties. American journal of sociology, 78(6): 13601380.

Griep, Y., \& Vantilborgh, T. 2018. Reciprocal effects of psychological contract breach on counterproductive and organizational citizenship behaviors: The role of time. Journal of Vocational Behavior, 104(Supplement C): 141-153.

Hansen, M. T. 1999. The search-transfer problem: The role of weak ties in sharing knowledge across organization subunits. Administrative science quarterly, 44(1): 82-111.

Hawkins, R. L., \& Maurer, K. 2009. Bonding, bridging and linking: how social capital operated in New Orleans following Hurricane Katrina. British Journal of Social Work, 40(6): 1777-1793.

Ho, V. T. 2005. Social influence on evaluations of psychological contract fulfillment. Academy of Management Review, 30(1): 113-128.

Ho, V. T., \& Levesque, L. L. 2005. With a Little Help from My Friends (and Substitutes): Social Referents and Influence in Psychological Contract Fulfillment. Organization Science, 16(3): 275-289.

Ho, V. T., Rousseau, D. M., \& Levesque, L. L. 2006. Social networks and the psychological contract: Structural holes, cohesive ties, and beliefs regarding employer obligations. Human Relations, 59(4): 459-481.

Ibarra, H. 1993. Network Centrality, Power, and Innovation Involvement: Determinants of Technical and Administrative Roles. The Academy of Management Journal, 36(3): 471-501.

Ibarra, H., \& Andrews, S. B. 1993. Power, social influence, and sense making: Effects of network centrality and proximity on employee perceptions. Administrative science quarterly: 277303.

Jenkins, R. 2014. Social identity: Routledge.

Jokisaari, M., \& Nurmi, J.-E. 2009. Change in newcomers' supervisor support and socialization outcomes after organizational entry. Academy of Management Journal, 52(3): 527-544.

Jokisaari, M., \& Nurmi, J.-E. 2012. Getting the right connections? The consequences and antecedents of social networks in newcomer socialization. The Oxford handbook of organizational socialization: $78-96$.

Kammeyer-Mueller, J., Wanberg, C., Rubenstein, A., \& Song, Z. 2013. Support, Undermining, and Newcomer Socialization: Fitting in During the First 90 Days. Academy of Management Journal, 56(4): 1104-1124.

Katz, R., Tushman, M., \& Allen, T. J. 1995. The Influence of Supervisory Promotion and Network Location on Subordinate Careers in a Dual Ladder RD\&E Setting. Management Science, 41(5): 848-863.

Kovanovic, V., Joksimovic, S., Gasevic, D., \& Hatala, M. 2014. What is the source of social capital? The association between social network position and social presence in communities of inquiry.

Lazer, D., Rubineau, B., Chetkovich, C., Katz, N., \& Neblo, M. A. 2008. Networks and political attitudes: Structure, influence, and co-evolution.

Levin, D. Z., \& Cross, R. 2004. The strength of weak ties you can trust: The mediating role of trust in effective knowledge transfer. Management science, 50(11): 1477-1490. 
Lin, N., Ensel, W. M., \& Vaughn, J. C. 1981. Social resources and strength of ties: Structural factors in occupational status attainment. American sociological review: 393-405.

Louis, M. R. 1980. Surprise and Sense Making: What Newcomers Experience in Entering Unfamiliar Organizational Settings. Administrative Science Quarterly, 25(2): 226-251.

Maitlis, S., \& Christianson, M. 2014. Sensemaking in Organizations: Taking Stock and Moving Forward. The Academy of Management Annals, 8(1): 57-125.

Meyerson, D., Weick, K. E., \& Kramer, R. M. 1996. Swift trust and temporary groups. Trust in organizations: Frontiers of theory and research, 166: 195.

Mizruchi, M. S., \& Stearns, L. B. 2001. Getting deals done: The use of social networks in bank decision-making. American sociological review: 647-671.

Morrison, E. W. 1993. Newcomer information seeking: Exploring types, modes, sources, and outcomes. Academy of management Journal, 36(3): 557-589.

Morrison, E. W. 2002. Newcomers' Relationships: The Role of Social Network Ties during Socialization. The Academy of Management Journal, 45(6): 1149-1160.

Nahapiet, J. 2011. A social perspective: Exploring the links between human capital and social capital. The Oxford handbook of human capital: 71-95.

Nelson, D. L., \& Quick, J. C. 1991. Social support and newcomer adjustment in organizations: Attachment theory at work? Journal of organizational behavior, 12(6): 543-554.

Podolny, J. M., \& Baron, J. N. 1997. Resources and relationships: Social networks and mobility in the workplace. American sociological review: 673-693.

Rousseau. 1995. Psychological contracts in organizations : understanding written and unwritten agreements. Thousand Oaks: Thousand Oaks : SAGE Publications.

Rousseau. 2001. Schema, promise and mutuality: The building blocks of the psychological contract. Journal of Occupational and Organizational Psychology, 74(4): 511-541.

Rousseau, D. M. 2000. Psychological contract inventory technical report: Pittsburgh, USA: Carnegie Mellon University.

Rowley, T. J. 1997. Moving beyond dyadic ties: A network theory of stakeholder influences. Academy of management Review, 22(4): 887-910.

Sandberg, J., \& Tsoukas, H. 2015. Making sense of the sensemaking perspective: Its constituents, limitations, and opportunities for further development. Journal of Organizational Behavior, 36(S1): S6-S32.

Sandefur, R. L., \& Laumann, E. O. 1998. A paradigm for social capital. Rationality and society, 10(4): 481-501.

Schilling, M. A., \& Fang, C. 2013. When hubs forget, lie, and play favorites: Interpersonal network structure, information distortion, and organizational learning. Strategic Management Journal, 35(7): 974-994.

Scott, C., \& Hofmeyer, A. 2007. Networks and social capital: a relational approach to primary healthcare reform. Health Research Policy and Systems, 5(1): 9.

Seeck, H., \& Parzefall, M.-R. 2008. Employee agency: challenges and opportunities for psychological contract theory. Personnel Review, 37(5): 473-489.

Seibert, S. E., Kraimer, M. L., \& Liden, R. C. 2001. A social capital theory of career success. Academy of management journal, 44(2): 219-237.

Shah, P. P. 1998. Who are employees' social referents? Using a network perspective to determine referent others. Academy of Management Journal, 41(3): 249-268.

Shea, C. T., \& Fitzsimons, G. M. 2016. Personal goal pursuit as an antecedent to social network structure. Organizational Behavior and Human Decision Processes, 137: 45-57.

Shore, L., \& Tetrick, L. 1994. The psychological contract as an explanatory framework in the employment relationship. Journal of Organizational Behavior, 1: 91.

Smirnov, I., \& Thurner, S. 2016. Formation of homophily in academic performance: students prefer to change their friends rather than performance. arXiv preprint arXiv:1606.09082. 
Soda, G., \& Usai, A. 1999. 11 The dark side of dense networks. Interfirm networks: Organization and industrial competitiveness: 276.

Sparrowe, R. T., \& Liden, R. C. 1997. Process and structure in leader-member exchange. Academy of management Review, 22(2): 522-552.

Sparrowe, R. T., Liden, R. C., Wayne, S. J., \& Kraimer, M. L. 2001. Social networks and the performance of individuals and groups. Academy of management journal, 44(2): 316-325.

Stones, R. 2005. Structuration theory: Wiley Online Library.

Tadepalli, R. 1992. Marketing control: reconceptualization and implementation using the feedforward method. European Journal of marketing, 26(1): 24-40.

Tasselli, S., Kilduff, M., \& Menges, J. I. 2015. The microfoundations of organizational social networks: A review and an agenda for future research. Journal of Management, 41(5): 1361-1387.

Thomas, H. D. C., \& Anderson, N. 1998. Changes in newcomers\&\#039; psychological contracts during organizational socialization: a study of recruits entering the British Army. Journal of Organizational Behavior, 19(S1): 745-767.

Tomprou, M., \& Nikolaou, I. 2011. A model of psychological contract creation upon organizational entry. Career development international, 16(4): 342-363.

Tomprou, M., Rousseau, D. M., \& Hansen, S. D. 2015. The psychological contracts of violation victims: A post-violation model. Journal of Organizational Behavior, 36(4): 561-581.

Tsai, W. 2001. Knowledge transfer in intraorganizational networks: Effects of network position and absorptive capacity on business unit innovation and performance. Academy of management journal, 44(5): 996-1004.

Van de Ven, A. H., \& Poole, M. S. 1995. Explaining development and change in organizations. Academy of management review, 20(3): 510-540.

Van Maanen, J., \& Schein, E. 1979. Toward a theory of organizational socialization. In BM Staw (Ed.), Research in organizational behavior (Vol. 1).

Weick, K. E. 1995. Sensemaking in organizations. Thousand Oaks: Thousand Oaks : Sage Publications.

Yuan, Y. C., \& Gay, G. 2006. Homophily of network ties and bonding and bridging social capital in computer-mediated distributed teams. Journal of Computer-Mediated Communication, 11(4): 1062-1084. 


\section{FIGURE 1}

\section{Co-evolutionary model of newcomers' psychological contract formation and social networks}

Anticipation Socialization Stage: Preentry

\section{Psychological contract}
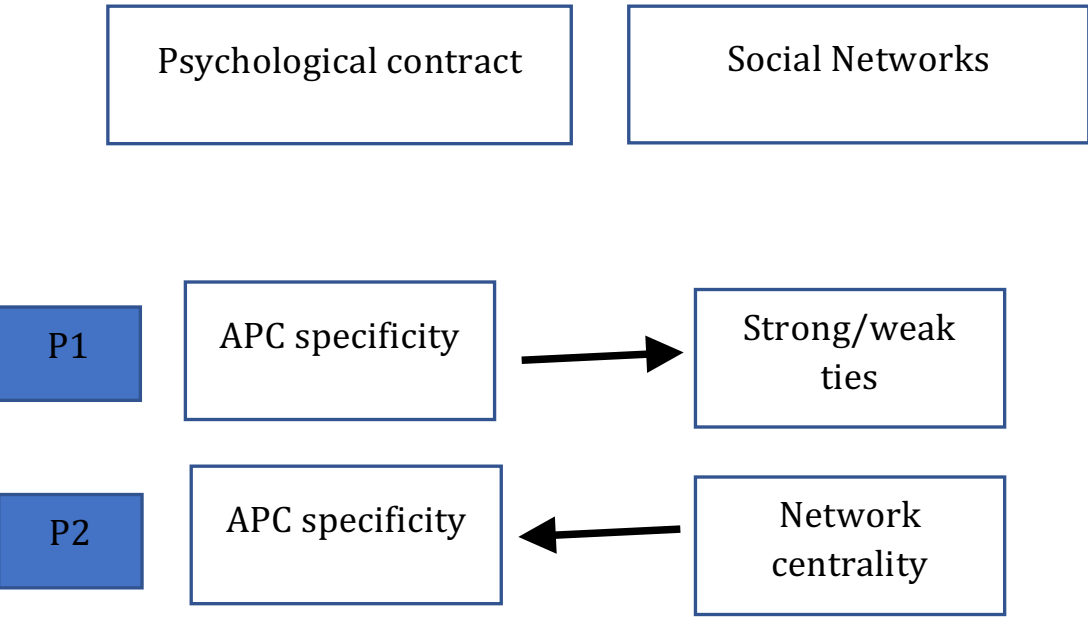

Encounter Socialization Stage: Postentry

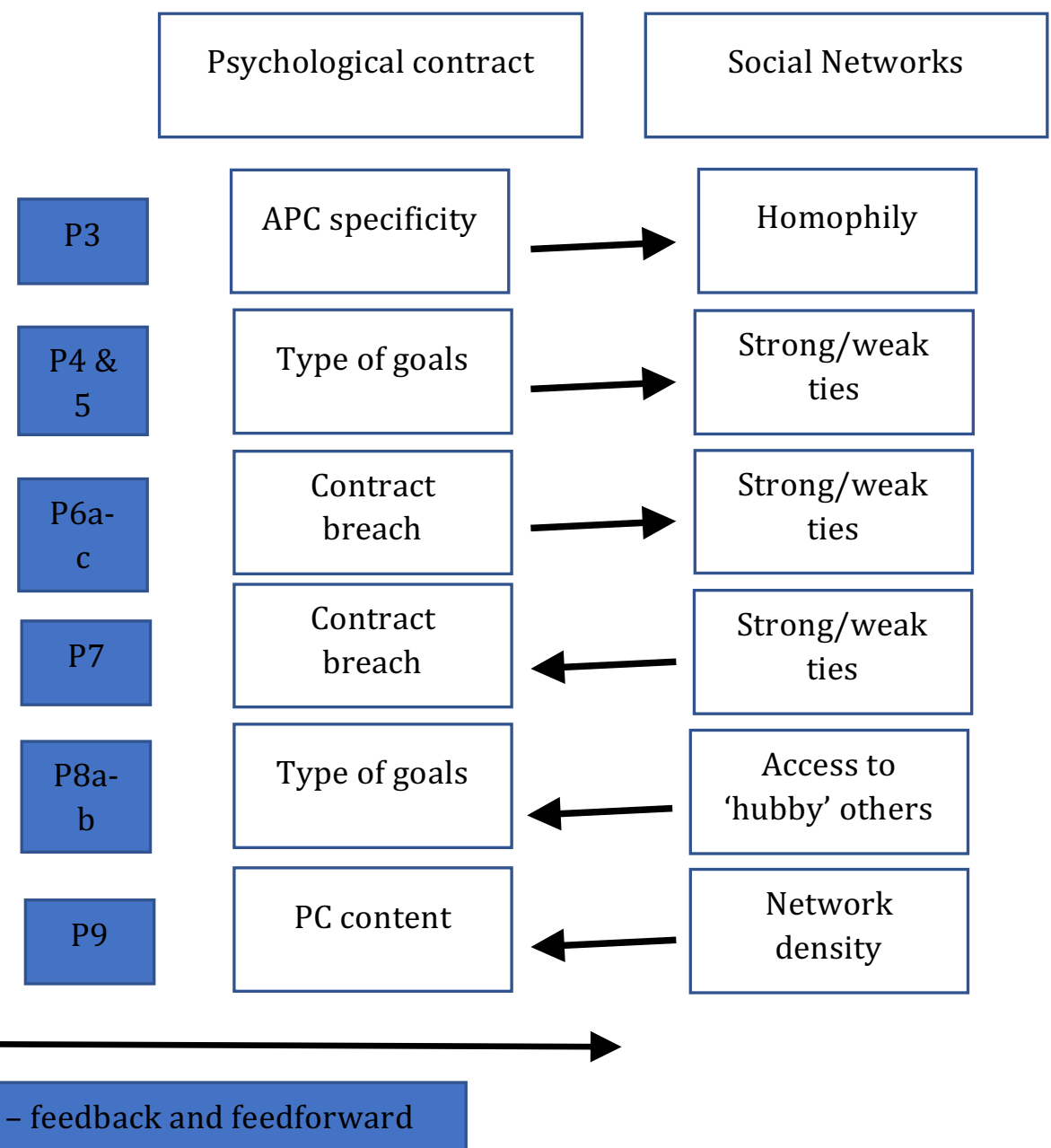

